\title{
THE BENEFITS OF COLLABORATION TO
}

\section{GRADUATE EDUCATION}

\author{
George S. Wilson \\ Higuchi Professor of Chemistry and Pharmaceutical Chemistry \\ University of Kansas
}

Collaboration is, of course, a critical aspect of human behavior and, as such, has been extensively studied by social scientists. In a recent book, Organizing Genius: The Secrets of Creative Collaboration, Bennis and Biederman ${ }^{1}$ analyze the activities and performance of such diverse groups as: the Skunk Works, the special group at Lockheed that designed in 180 days the first U.S. jet fighter as well as many other innovative aircraft; the Palo Alto Research Center (PARC) of Xerox that designed the first PC in the 1970 's, but failed to commercialize it; and the campaign committee that directed President Clinton's 1992 bid for the presidency. The groups that succeeded did so because of the interaction of exceptional talent, an opportunity not open to all of us, but there are still some important take-home lessons to be appreciated. We need to select the right collaborators, make sure that the mission is clearly defined and understood by all, provide the resources necessary to carry out the project, and make sure that the accomplishments of the group are effectively communicated to the scholarly community. Perhaps most important, however, is a firm belief in the project and its urgency, and the need to complete it before anyone else does.

The subject of collaboration within the academic environment has also attracted significant attention. Such questions as "Is collaboration beneficial to graduate students?" and "How can collaboration be enhanced?" have been the subjects of recent activities supported by the National Science Foundation. In a study performed in the early 1990s, Anderson ${ }^{2}$ examined collaboration patterns in the physical and natural sciences, engineering, and in the social sciences. The focus was on the most fundamental of collaborative interactions - the doctoral candidate with his/her mentor. In the physical and natural sciences collaboration is very extensive, and the problem a candidate pursues may well be chosen by the mentor. This is, of course, logical since financial support derived from a successful grant proposal will be needed to carry out the work. By contrast, in the social sciences the doctoral candidate may be required to choose the problem of study and to carry it out, with minimal involvement of the mentor. In departments where the level of collaboration is high, several attitudes emerge. Students believe the graduate experience better prepares them for future professional activities, the interactions with their mentors are more productive, and these interactions 
better encourage self-reliance on the part of the student. Collaboration also seems to lead to a more active student role in departmental activities and "fosters an atmosphere of respect and caring."

In 1995, the National Science Foundation sponsored a workshop entitled, Connecting and Collaborating: Issues for the Sciences. ${ }^{3}$ The participants came from many academic disciplines within the sciences in the U.S. and abroad, and the focus of their discussion was to "understand the scientific, social, and economic impacts of using advanced communications technology." It was recognized that along with greater accessibility of information come "questions of intellectual property, confidentiality, authorial credit, institutional allegiance, privacy, and questions of tenure and promotion." Because information appearing on the Web is not always peerreviewed, its reliability must necessarily be questioned. However, the ability to remotely access information and even to conduct online experiments remotely in real-time, offers significant opportunity to expand available resources. Technical barriers to connectivity still exist, but here in Kansas and through the leadership of Ted Kuwana and the EPSCoR program, a regional high speed network will become a reality. The Workshop also emphasized the importance of "scientific" (I might say cultural) barriers to effective communication and collaboration. My research demands that I interact with physicians, polymer chemists, and bioengineers who have very different ways of looking at the same problem. Therefore it is necessary to establish a common language and carefully define the approaches to the problem so that everyone understands the rationale.

One of the most intriguing aspects of the Internet is the manner in which it has promoted what is referred to as the "democratization" of science. I have received e-mail messages from a graduate student in Indonesia who wanted me to explain a difference of opinion on a scientific point, a high school student in Toronto writing a paper based on my research interests, or a father in Louisville telling me how urgent it is for my research to be brought to a successful conclusion. I continue to be amazed at how much information is available about what I am doing (information not even generated by me), and how, as a result of the Internet, people do not hesitate to "bother" me concerning a point of interest to them. I encourage my students to inquire of faculty elsewhere if they have questions, and many faculty have been most generous with their input.

If many of the tools for collaboration are in place, what then are the advantages of collaboration in the context of graduate education?

Access to expertise and resources not available "in-house"

$>$ Opportunity for student to "try wings" 
$>$ Exposure to different approaches to the same research problem

$>$ Student experience in managing collaboration

$>$ Exposure to different research environments

$>$ Experience in communication and problem solving

There are, however, barriers to success in collaboration that must be overcome:

Who is in control?

$>$ Who gets the credit?

$>$ Intellectual property

$>$ Conflicts in management style

$>$ Ineffective communication

$>$ Lack of definition of the experimental plan

I would like to talk about three types of collaborative experiences that I have had over the years: (1) with a colleague in the same department, but a different subdiscipline of chemistry, for 25 years; (2) with three investigators in France, supported continuously during this period by the National Institutes of Health (NIH), for 15-years; (3) industrial collaboration under the support of an $\mathrm{NIH}$ Training Grant. These experiences must be regarded as anecdotes as I am in no position to compete with people who study such problems systematically and with a much broader base of examples.

In the first instance, there have now been about 17 graduate students and post-doctoral research associates who have worked under our joint direction. It is made clear to all of these persons at the beginning that they have to satisfy both of us, even if the advice we give seems to be in conflict. This collaboration involves synthesizing compounds (other group) and making physical measurements on them (my group). The issue from a scientific point of view is a central question in chemistry: Can the relationship between the structure of a molecule and its reactivity be predicted and understood? The students are required to manage their collaborations with the other research group. They learn that what is easy for a person trained in one subdiscipline is not necessarily readily implemented by someone trained in another area. Regular joint group meetings emphasize good communication and the need for putting the problem under study in the appropriate context. In this example the institutional and cultural differences are minimal, thus greatly simplifying interactions. Great care is, however, taken to assure proper credit in the form of author order on publications.

The second example presents a large variety of challenges because there are conventional cultural differences (French vs. American) as well as the differences in thinking between chemists and physicians or biomedical 
engineers. Research is financed in a very different way in France, and such differences have to be taken into account. The structure is much more hierarchical than in the U.S., and giving graduate students too much latitude in decision-making can create problems. When students come for visits of a few weeks or months, I place the responsibility for development of an experimental plan in their laps, subject to my approval. The collaborating students teach each other, not only about the common science, but also about the way they live and their views on being a professional scientist. When French students are in the U.S. they are obliged to speak English, however, if they wish to write progress reports in French, then my students are required to read them. It is unfortunate that, in general, I cannot enforce the reciprocal arrangement, namely that U.S. students should speak French when they are in France. Although my French collaborators all speak English, they do not like to be reminded that the lingua franca is English and not French. (Parenthetically, I would like to see a speaking knowledge of a foreign language be a requirement for science students.) Because communication is so important, we have made use of the Internet and its predecessors for virtually the entire duration of this collaboration. Manuscripts and grant proposals are routinely shipped back and forth electronically thus effectively closing the geographical gap. We have, however, come to realize the significant limitations of this technology in promoting and maintaining human relations. For example, if controversial issues arise, we know that they may not be easily resolved by e-mail because it is impossible to attach the proper level of emotion to the communication with the result that carelessly chosen words can cause an otherwise good discussion to run off track. Personal contact is also very important, and the graduate students must be familiar with their counterparts in France. To their credit the Europeans, through the European Community, now have in my field an established system for graduate student exchange that we would do well to emulate. We have also had to deal with intellectual property issues, which are complicated primarily by the differences in patent law and institutional procedures for dealing with them.

The final experience in collaboration involves an industrial internship that is part of an NIH Training Grant in Biotechnology, the brainchild of Professor Ronald Borchardt of the Department of Pharmaceutical Chemistry at the University of Kansas. The traineeship requires an internship, typically of 3-6 months duration, that occurs late in the tenure of a graduate student, i.e., at a point where he/she has a good grasp of the research problem to be solved. The ground rules are quite specific: the problem to be worked on must be of interest to the particular group in which the student will be working, but must also be relevant to the student's Ph.D. dissertation. The work must be publishable, meaning that only a minimal delay ( 3 months) is permitted to establish the possible need for patent disclosure. Should intellectual property 
be developed during the tenure of the student, an orderly approach to establishment of ownership is outlined. The existence of a model agreement raises everyone's optimism that this seemingly insurmountable barrier can be penetrated. A key to success in this endeavor is finding the "right fit" for the student and his/her industrial mentor. This is accomplished by having a large list of potential mentors. Generally industry will pay travel expenses to and from the site and subsistence support. The cost is quite modest: typically less than $\$ 10,000$. First, a criterion for the collaboration is the possibility that the student can carry out work that could not be carried out at KU, because the equipment or expertise does not exist. Thus the student is delighted to be able to realize certain goals that previously seemed out of reach. Even in such a short time, the student comes to realize that much industrial research is "fire fighting," i.e., solving urgent short-term problems quite unlike the indepth studies that often characterize academic research. The results have been quite spectacular. Students have returned with a level of maturity and enhanced confidence in their own abilities. They have had no problem getting jobs because they already know what kinds of questions interviewers are going to ask and why.

Perhaps one of the most important lessons to be learned from the collaborations that I have described is the realization that it is not sufficient to be well grounded in the fundamentals of one's field. It is of paramount importance to be a problem solver, and one who can effectively communicate with other collaborators and reinforce the group's understanding of the goals to be achieved.

I would like to express my appreciation to Professor Janet $B$. Robinson, Department of Chemistry at KU, for her very valuable input to this presentation.

\section{Notes}

${ }^{1}$ Bennis, W. and Biederman, P.W., Organizing Genius: The Secrets of Creative Collaboration, Addison-Wesley, New York, 1997.

2 Anderson, M.S., Collaboration, the Doctoral Experience, and the Departmental Environment, Review of Higher Education, 19, 305-326 (1996).

${ }^{3}$ NSF Division of Social, Behavioral, and Economic Research, Workshop on Connecting and Collaborating: Issues for the Sciences, University of California-San Diego, June 1995.

Web Site: www.nsf.gov/sbe/sber/sociol/works2.htm 